УДК $811.111: 81 ’ 42: 81 ’ 373.48$

DOI https://doi.org/10.26661/2414-1135-2021-82-19

\title{
ОСОБЛИВОСТІ ВЖИВАННЯ АНГЛОМОВНОГО СЛЕНГУ НА ПОЗНАЧЕННЯ ГРОШЕЙ В АМЕРИКАНСЬКИХ РЕП-ТЕКСТАХ
}

\author{
Козубай I. B. \\ старший викладач кафедри сочіально-гуманітарних дисциплін \\ Дніпропетровський державний університет внутрішніх справ \\ пр. Гагаріна, 26, Дніпро, Україна \\ orcid.org/0000-0001-9667-8446 \\ ikozubay@gmail.com \\ Хаджи А. Ю. \\ старший викладач кафедри соиіально-гуманітарних дисичилін \\ Дніпропетровський державний університет внутрішніх справ \\ пр. Гагаріна, 26, Дніпро, Україна \\ orcid.org/0000-0002-7140-0314 \\ kulishanna89@gmail.com \\ Гудова А. В. \\ здобувач вищої освіти юридичного факультету \\ Дніпропетровський державний університет внутрішніх справ \\ пр. Гагаріна, 26, Дніпро, Украӥна \\ orcid.org/0000-0003-3732-0385 \\ kartrucanastasia@gmail.com
}

\begin{abstract}
Ключові слова: типологія сленгових виразів, семантичні групи, американський реп-дискурс, хіп-хоп культура, валюта.
\end{abstract}

3 огляду на активне розширення міжнародної співпраці, глобалізації та Інтернет-культури поширення сленгу не тільки не припиняється, але й зростає. Сучасне життя суспільства, зокрема молоді, також характеризується стрімким проникненням реп-культури, у зв'язку з чим лінгвістичні дослідження цього стилю нині є дуже перспективними та актуальними, адже словник хіп-хоп культури вважається одним із найпродуктивніших способів поповнення лексичного запасу англійської мови. Ця стаття присвячена вивченню поняття та функціонування сленгових слів та виразів на позначення грошових одиниць у новітньому американському реп-дискурсі. Практична частина цього дослідження містить аналіз причин і особливостей використання сленгових лексичних одиниць у текстах сучасних американських репвиконавців, таких як Kanye West, Jay-Z, Kendrick Lamar, The Notorious B.I.G., Wiz Khalifa, Headie One, Trinidad James та інші. Авторами роботи було здійснене групування знайденого сленгу за семантичним значенням та 3'ясовано закономірність його використання. У рамках проведеної роботи було виявлено, що сленгові терміни для позначення грошей часто пов'язані iз зовнішнім виглядом і характеристиками банкнот і монет, їх вартістю, історичними асоціаціями або відповідними грошовими одиницями. Також варто зазначити, що частина 3 них стала домінуючим способом позначення валюти і навіть перейшла в загальновживані слова, про що свідчать сучасні словники. Наукове дослідження доводить, що сленг насамперед відображає реальність та використовується як прийом непрямої комунікації, під час якої розуміння висловлювання включає безпосередньо зміст, який власне не міститься в ньому, але потребує додаткових інтерпретаційних зусиль із боку адресата. У рамках одного мовного співтовариства деякі сленгові терміни розрізняються залежно від соціальних, етнічних, економічних і географічних шарів. Перспективність подальшого вивчення типології цих сленгових виразів зумовлена їх поширеністю в сучасному американському реп-дискурсі, що і буде становити предмет дослідження подалыших наукових робіт. 


\title{
THE FEATURE OF ENGLISH SLANG USAGE THAT DENOMINATES MONEY IN AMERICAN RAP LYRICS
}

\author{
Kozubai I. V. \\ Senior Lecturer at the Social and Humanities Chair \\ Dnipropetrovsk State University of Internal Affairs \\ Haharina avenue, 26, Dnipro, Ukraine \\ orcid.org/0000-0001-9667-8446 \\ ikozubay@gmail.com \\ Khadzhy A. Yu. \\ Senior Lecturer at the Social and Humanities Chair \\ Dnipropetrovsk State University of Internal Affairs \\ Haharina avenue, 26, Dnipro, Ukraine \\ orcid.org/0000-0002-7140-0314 \\ kulishanna89@gmail.com \\ Hudova A. V. \\ 3rd year Student at the Faculty of Law \\ Dnipropetrovsk State University of Internal Affairs \\ Haharina avenue, 26, Dnipro, Ukraine \\ orcid.org/0000-0003-3732-0385 \\ kartrucanastasia@gmail.com
}

Key words: typology of slang expressions, semantic groups, American rap discourse, hip-hop culture, currency.
As a result of the powerful expansion of international collaboration, globalization and Internet culture, the spread of slang does not stop but also grows among a wide range of people. The modern life of society, in particular young people, is also characterized by the rapid penetration of rap culture. In this connection, linguistic studies of this style are still very promising and relevant because the vocabulary of hip-hop culture is considered one of the best ways of updating the vocabulary of the English language. Although many intelligent people consider slang to be of lower acceptability in society, the trend is more obvious that the use of slang expressions is noticeably increasing. We can see American slang is becoming more and more widely used and plays an increasingly influential role in the everyday discourse of American English. This article is devoted to the study of the concept and functioning of slang words and expressions for the designation of currency units in the latest American rap discourse. The practical part of this research contains an analysis of the reasons and features of the use of slang lexical units in the lyrics of modern American rap artists, such as Kanye West, Jay-Z, Kendrick Lamar, The Notorious B.I.G., Wiz Khalifa, Headie One, Trinidad James etc. The authors of this study have grouped the finding slang by semantic meaning and have clarified the regularity of its use. The work has found that slang terms for money are often associated with the appearance and characteristics of banknotes or coins, their value, historical associations or relevant currencies. It is also worth noting that some of them have become the dominant way of denoting currency and have even become common words, as evidenced by modern dictionaries. Scientific research has proved that slang primarily reflects reality and has been used as one of the methods of indirect communication. The understanding of the statement includes the content itself, which is not contained in it but requires additional interpretive effort on the part of the recipient. Within one language community, some slang terms differ depending on social, ethnic, economic, and geographical backgrounds. Prospects for further study of the typology of these slang expressions is due to their prevalence in modern American rap discourse, which will be the subject of research in future scientific papers. 
Постановка проблеми. Мова кожної нації постійно розвивається і поповнюється новими лексемами як шляхом виникнення нових слів у межах материнської мови, так і шляхом запозичення з інших мов або шляхом переходу зі сленгу. Одним із важливих питань сучасної лінгвістики $\epsilon$ вивчення мовлення молодіжних сленгів, які в першу чергу можна зустріти в сучасних фільмax, книгах та піснях. Кілька останніх десятиліть реп-культура дуже стрімко входить в наше повсякденне життя. Реп-музика - один з елементів хіп-хопу, це - форма римованої лірики, яку читають ритмічно під музичні інструменти, із семплюванням музичного фону, скретчами та міксами ді-джеїв. Поширення хіп-хопу дає виконавцям змогу більш творчо підходити до своїх треків, а тому з'являються нові підстилі цього жанру. Ріст цього жанру пов'язаний 3 активним використанням його лексики, яка виконує функцію сполучної ланки реперів усього світу. Афроамериканська англійська - ебонікс - мова, основною сферою вживання якої $є$ хіп-хоп культура, зокрема реп, стала загальновживаною серед молоді, як темношкірого, так і білого населення, і являє собою гарячу тему в наукових колах $[4$, с. 235].

Вивченням репу нині займається широке коло науковців - лінгвісти та літературознавці, культурологи та соціологи. Так, В. Лукова, Д. Садикова та Дж. Огбар аналізують реп як соціальне та культурологічне явище. Вчені-філологи О. Гриценко та Л. Дуняшева розглядаються його жанрові та лінгвістичні особливості, аналізуючи лінгвокультурні та соціолінгвістичні особливості. Проте варто зазначити, що українські лінгвісти рідко звертаються до вивчення репу, незважаючи на його широку популярність серед молоді. Таким чином, ми вважаємо різноаспектні філологічні дослідження цього явища актуальними і доречними.

Об'єктом нашого дослідження вибрано сленгові слова зі значенням «гроші», а саме такий сленг, що функціонує в американських реп-текстах, зокрема таких яскравих і найбільш популярних представників цієї культури сьогодення, як Kanye West, Jay-Z, Kendrick Lamar, The Notorious B.I.G., Wiz Khalifa, Headie One, Trinidad James та багато інших. Предметом нашого дослідження стали стали штампи англомовного суспільства, що відображаються в сленгових словах та виразах зі значенням «гроші» сучасних американських реп-пісень. Метою статті $\epsilon$ визначення лінгво-семантичних особливостей використання сленгових виразів у структуруванні американських реп-пісень. Імплементація поставленої мети передбачає розв'язання таких завдань: проаналізувати сленгові одинці зі значенням «гроші», згрупувати їх за семантичним значенням, визначити їх роль та функції в англомовному реп-дискурсі та 3'ясувати закономірності використання.
Виклад основного матеріалу дослідження. Реп є одним із найпопулярніших жанрів сучасної музики. Виконавці цього стилю стали свого роду ідолами для певних людей. Саме тому вони задають стиль в одязі, лексиці, зачісках і так далі. Такі окремі лексичні пласти, як жаргонізми, арго, вульгаризми, нецензурна лексика, діалектизми, просторіччя та професіоналізми, нині злилися разом, утворюючи групу під назвою «сленг». Найбільш часто він вживається серед молоді як засіб самовираження, спосіб зашифрованої мови, роблячи мову більш емоційною і яскравою. Сленгові позначення на елементарні слова в реп-текстах $\epsilon$ дуже популярними серед виконавців. А тому кожен репер дає своїм текстам родзинку у вигляді нового зашифрованого слова.

У нашому недосконалому світі гроші відіграють важливу роль. Різні соціальні групи мають із ними різні відносини, але стикатися 3 грошима доводиться щодня кожній людині. Про гроші так багато говориться в репі, що людям доводиться придумувати нові способи сказати це, щоб їх впізнавали і вони не здавалися звичайними. Таким чином виникає безліч назв, які відображають певне ставлення до грошей. Сленгові терміни для позначення грошей часто пов'язані із зовнішнім виглядом і характеристиками банкнот або монет, їх вартістю, історичними асоціаціями або відповідними грошовими одиницями.

У процесі аналізу матеріалу американських реп-текстів було знайдено понад 100 різних назв грошей, серед яких ми виділили кілька груп за їх семантичним значенням, які найчастіше зустрічаються.

1. Перша і найпопулярніша група-їжа. В основному це продукти зеленого кольору - cabbage (капуста), lettuce (салат-лутук), green beens (зелена квасоля), spinach (шпинат), zucchini (кабачки), broccoli (броколі). Це пов'язано $з$ тим, що доларова банкнота і листові овочі мають один і той самий зелений колір: Ahh, who wanna bet us that we don't touch lettuce? Stack cheddars forever, live treacherous, all the et ceteras («Dead Presidents II» by JAY-Z). One in the chamber, the safety is off release. Straight at your dome, holmes, I wanna see cabbage («Ready to Die» by The Notorious B.I.G.). They know I got that broccoli, so I keep that Glock on me («Put on» by Jeezy). In it for the green zucchini, so we can get a new Beemie For Babu, the 1 and 2's genie («The Unexpected» by DJ Babu).

Як зазначає О. Халапсіс, «<...> гроші - це те, що ми вважаємо грошима. На ранніх етапах історії людства грошима виступали речі» [5, с. 128]. Тому реп-виконаці вживають у своїх текстах й інші види їжі: I check chedda like a food inspector («Interlude» by Jay-Z). Chedda - чеддер (англійський сир), особливо актуальна сленгова одиниця серед темношкірих американських реперів у 
зв'язку з тим, що населення нью-йоркських барроуз - Квінса, Брукліна, Стейтен Айленда - стояло в довгих чергах, щоб отримати свій пайок, а потім часто використовувало сир як валюту.

I'll never fade away, I'll never fade away, I know my fate And I'm on the grind for this cake, I'ma get it or die tryin' («Sing About Me, I'm Dying of Thirst» by Kendrick Lamar). Cake - торт - означає великі пачки грошей, які викладені одна на одну.

Nah, I don't spin on my head I spin my work in the pot, so I can spend my bread («Blue Magic» by JAY-Z). Хліб в усі часи вважався одним з основних продуктів, без яких людина не може вижити.

2. У другій групі ми виділили імена відомих людей, які зображені на грошових купюрах, а тому, коли чуємо ці прізвища, йде асоціація з грошима:

I'm married to Elizabeth, that's my wife (Shawty). Anything green get bun, still do it like I done it like half my life («Golden Boot» Headie One), I told Elizabeth marry me (Marry me) They leave the cash on me («Fo' Real» by M Huncho). Elizabeth - королева Слизавета II, яка $є$ главою держави Сполученого Королівства, і тому іiї обличчя зображене на всій британській валюті.

The way my pockets swell to the rims with Benjamins. Another honey's in the crib? Please, send her in («One More Chance» The Notorious B.I.G.); Mama always told me: "Boy, count your blessings." In God I trust, so I kept counting them Franklins («All Gold Everything» by Trinidad James). Franklin Бенджамін Франклін, колишній президент Америки, який зображений на 100 -доларовій купюрі.

I'm all about my Franklins, Lincolns, and Reagans. Whenever they make them, I shall hayve them («Barry Bonds» by Kanye West). Lincoln Авраам Лінкольн - 16-й президент США, визволитель американських рабів, національний герой США. Reagan - Рональд Вілсон Рейган, 40-й Президент США від Республіканської партії.

Blowin' fuck it I don't care, Jacksons flyin' everywhere («No Hands» by Waka Flocka Flame). Jacksons - Ендрю Джексон - президент, обличчя якого на 20-доларовій купюрі.

До групи відомих людей можна зарахувати відомий вираз «мертві президенти», Thinking, "How could I get some dead presidents?" I need money, I used to be a stick-up kid («Paid in Full» by Eric B. \& Rakim); I'm looking for Dead Presidents to represent Me. («The World Is Yours» by Nas) - стосується зображень культових померлих американських президентів на доларових банкнотах - готівка.

3. Третя група - це запозичені 3 інших мов слова, які означають місцеву валюту або вживаються на позначення грошей:

Come money dance with the good fellas. Hov keep gettin' that dinero, got it. («WithMeYouKnowIGotIt» by JAY-Z). Dinero 3 іспанської - гроші.
Making six doubloons, got a baby that's fixed to bloom («Nowalaters» by The Coup). Дублони використовували в іспанських країнах в 1700-х роках, вони стали відомими серед піратів як їх жаргон.

That don teven make sense, like dykes using dildos. So reach in your billfolds for ten ducats («Any Man» by Eminem). Дукати колись були золотими торговими монетами, а зараз це «герцогські монети».

Thats a credit card debtor guardin Plethoras of sheckles hard to get em («Gas» by InCredible). Шекель походить від біблійної валюти.

4. У четвертій групі ми виділили сленг, який означає якусь певну сумму грошей або велику їх кількість:

So if you send shots then you bet not miss. For a couple G's, send a couple G's ("Ain't That Some Shit» by J. Cole). $\boldsymbol{G}$ 's - це абревіатура від «grands» або «thousands», тобто на позначення 1000\$: Thirty grand for the Muller, that's a Chevy on my wrist («Levels» by Meek Mill).

$80 K$ just to know what time is it («I do» by Cardi B). K або G (grand) - лаконічні способи сказати «тисяча доларів» або згадати дорогу річ, вартість якої еквівалентна цій сумі.

Knock niggas out the box all the time, Niggas know my motherfuckin' repertoire, big ones (Uh-huh) («Incarcerated» by Raekwon). Big One - стодоларова банкнота. Також часто зустрічається така назва C-notes: He takin' all of my C-Notes (It's true), See, he has a gamblin' issue, He takes the cash and blows it all at casinos (Damn!) («III Mind of Hopsin 8» by Hopsin). C походить від латинського слова Centum, що означає 100. С також використовувалося як абревіатура для сотні римськими цифрами.

You need money? I got mine. More knots than E ric on Basketball Wives («Roman Reloaded» by Nicki Minaj). Knots - в перекладі «вузол», для реп-виконавців $\epsilon$ «пачкою грошей». Справа в тому, що в США купюри часто вже не складають стопкою, а згортають у трубочку. I чим товстіша така кругла пачка грошей, тим більше вона нагадує щільний вузол.

Найпопулярніше сленгове слово в цій группі це «gwop». Про це слово точно нічого не відомо, але $є$ кілька теорій. Цей термін може бути скорочений від іспанського guаро або guара, що означає «красивий». Але скоріше за все «gwop» став сленговим слово через торговців наркотиками в Гарлемі та Нью-Йорку для позначення «пристойної суми» зароблених грошей. Також є інша теорія, яка передбачає, що «gwop» - це абревіатура від імені Джорджа Вашингтона: Nah, you're not ready. Yeah, all Ineed is gwop («Lean and Bop» by J Hus). Countryside, where the gwops at. Jump in pics, you ain't bro, man, crop that («Next Up?» by CGM) Badman take your hands out your pockets. Trap, trap mash I get gwop in («Grip \& Ride» by Harlem Spartans). 
5. Остання група, яку ми виділили, - це лексичні одиниці, які прийшли зі сленгу, проте стали загальновживаними зараз, про що свідчать сучасні словники:

He only wanna see that ass in reverse. Twothousand-dollar bag with no cash in your purse («Blood on the Leaves» by Kanye West). Cash - це паперові гроші, які легко заховати від податків і які активно використовуються в проведенні тіньових операцій.

Backstabbers, scheamin for banknotes. And all of you out there know what I'm talkin bout - походить від англійського bank - банк i note - розписка («This One's for Me» by Ice-T).

He say he gettin' money but I know that's a lie. I see ones and fives in your bankroll right now. But unh-unh you ain't flexin' boy you need some exercise («Macaroni Time» by Chief Keef). Bankroll - це сума грошей на рахунку гравця, яку він використовує для гри в покер на гроші.

I'm from Cleveland where they trap shit. Five bucks for the catfish, five bucks for the bad bitch. Five bucks in a drought in this city could get you a piece of that cactus («Miss Me?» Machine Gun Kelly). У певний період це було найпопулярніше сленгове слово не тількі в реп-музиці, а й в англійській мові. Версій його походження дуже багато, але є дві основні. Перша - це скорочення від buckskin (оленяча шкура), вважають, що це пов'язано 3 першим фондовим ринком в Америці, а саме ринком шкур. Інша версія пов'язана 3 Громадянською війною в Америці. Президент Лінкольн гостро потребував грошей, але ніяк не міг отримати кредити від європейських банків. Тоді він вирішив провести велику грошову емісію - за два роки було випущено майже півмільярда доларів. Щоб відрізняти нові купюри, їхній зворотний бік стали фарбувати в зелений колір, за що американці прозвали їx greenbacks (зеленими спинками).

Висновки і перспективи подальших розробок. Отже, зазначимо, що більше 90\% всіх реп-пісень обертаються навколо теми грошей або розкоші, яку можна купити за гроші. Проведене нами дослідження демонструє той факт, що використання в хіп-хопі сленгових виразів на тему грошей дуже подобається виконавцям. Для американських реперів наявність великої кількості грошей безпосередньо асоціюється 3 успіхом і владою, адже варто пам'ятати, що більшість із них - вихідці з робітничого класу. Використання сленгу в американському реп-дискурсі $є$ досить популярним i використовується 3 метою створення експресивних образів, привернення уваги та доступності викладу, а також для введення в текст культурного маркера, який буде зрозумілий для більшості. Перспективність вивчення типології сленгових одиниць зумовлена їх поширеністю в сучасному американському реп-дискурсі, що $\mathrm{i}$ буде становити предмет дослідження у подальших наукових роботах.

\section{ЛITЕРАТУРА}

1. Genius. Community of contributors powers the world's biggest collection of song lyrics and musical knowledge. URL: https:/genius.com/

2. Ogbar J.O.G. Hip-Hop Revolution: The Culture and Politics of Rap, Lawrence : University Press of Kansas, 2007.

3. Urban Dictionary. URL: https://www.urbandictionary.com/.

4. Козубай I.В., Хаджи А.Ю. Лінгво-семантичні особливості використання прецедентних імен у структуруванні американських реп-пісень. Актуальні питання гуманітарних наук : зб. наук. праць молодих вчених Дрогобицькогодерж.пед.ун-туім.ІванаФранка. 2020. Том 2. С. 234-354.

5. Халапсис А.В. Мир без денег: Экономические и социокультурные трансформации эквивалента стоимости. Наукове пізнання: методологія та технологія. 2018. Вип. 1 (40). C. $126-135$.

\section{REFERENCES}

1. Genius. Community of contributors powers the world's biggest collection of song lyrics and musical knowledge. URL: https://genius.com/

2. Ogbar J.O.G. Hip-Hop Revolution: The Culture and Politics of Rap, Lawrence: University Press of Kansas, 2007.

3. Urban Dictionary. URL: https://www.urbandictionary.com/.

4. Kozubai, I., Khadzhy, A. (2020) The linguistic and semantic features of precedent names usage in structuring of American rap lyrics [Linhvo-semantychni osoblyvosti vykorystannia pretsedentnykh imen u strukturuvanni amerykanskykh reppisen] Aktualni pytannia humanitarnykh nauk: Collection of scientific works of Ivan Franko Drogobych State Pedagogical University, vol.2, pp. 234-354.

5. Halapsis, A.V. (2018) The World Without Money: Economic and Socio-Cultural Transformationsof the Value Equaivavelnt [Mir bez deneg: Ekonomicheskiye i sotsiokulturnyye transformatsii ekvivalenta stoimosti] Scientific knoweledge: methodology and technology. Vol. 1 (40), pp. 126-135. 